\title{
REVISTA VOZES DE PETRÓPOLIS: A PRESENÇA DOS FRANCISCANOS NA EDUCAÇÃO BRASILEIRA POR MEIO DE IMPRESSOS (1907-2003)
}

\author{
Claudino Gilz \\ FAE Centro Universitário \\ frclaudino@bomjesus.br \\ Cleonice Aparecida de Souza \\ PUC Campinas e USF \\ cleo120@gmail.com
}

\begin{abstract}
RESUMO
A presente pesquisa em andamento tem como objeto de estudo a revista Vozes de Petrópolis, editada pelos Franciscanos no Brasil e posta em circulação entre 1907 e 2003 pela Editora Vozes. Essa pesquisa, alinhada à linha de pesquisa Rastros: patrimônio cultural franciscano e educação, objetiva analisar a presença dos Franciscanos na educação brasileira por meio de impressos. Histórica e qualitativa, a metodologia privilegia a análise documental do contexto sociocultural do período (BENJAMIN, 2012), às lutas e resistências da Igreja Católica (LEÃO XIII, 1878), a história da leitura (CHARTIER, 1990 e 2002; DARNTON, 1992 e 2010) e a presença dos Franciscanos na história da educação brasileira (RÖWER, 1947; SINZIG, 1910).
\end{abstract}

Palavras-chave: Revista Vozes de Petrópolis. Franciscanos. História da Educação Brasileira.

\section{REVISTA VOZES DE PETRÓPOLIS - LA PRESENCIA DE LOS FRANCISCANOS EN EDUCACIÓN BRASILEÑA POR IMPRESIÓN}

\section{RESUMEN}

La presente investigación en progreso tiene como objeto de estudio la revista Vozes de Petrópolis, editada por franciscanos en Brasil y puesta en circulación entre 1907 y 2003 por Editora Vozes. La investigación, alineado con la línea de investigación Rastros: patrimônio cultural franciscano $e$ educação, tiene como objetivo analizar la presencia de franciscanos en la educación brasileña a través de materiales impresos. Histórica y cualitativa, la metodología privilegia el análisis documental del contexto sociocultural del período (BENJAMIN, 2012), las luchas y la resistencia de la Iglesia Católica (LEÃO XIII, 1878), la historia de la lectura (CHARTIER, 1990 e 2002; DARNTON, 1992 e 2010) y presencia de franciscanos en la historia de la educación brasileña (RÖWER, 1947; SINZIG, 1910).

Palabras-clave: Revista Vozes de Petrópolis. Franciscanos. Historia de la educación brasileña.

\section{REVISTA VOZES DE PETRÓPOLIS - THE PRESENCE OF FRANCISCANS IN BRAZILIAN EDUCATION BY PRINT}




\begin{abstract}
This research in progress has as object of study the magazine Vozes de Petrópolis, edited by Franciscans in Brazil and put into circulation between 1907 and 2003 by Vozes publishing company. This research, aligned with the research line Rastros: patrimônio cultural franciscano $e$ educação, aims to analyze the presence of Franciscans in Brazilian education through printed materials. Historical and qualitative, the methodology privileges documentary analysis of the socio-cultural context of the period (BENJAMIN, 2012), the struggles and resistance of the Catholic Church (LEÃO XIII, 1878), the history of reading (CHARTIER, 1990 e 2002; DARNTON, 1992 e 2010) and presence of Franciscans in the history of Brazilian education (RÖWER, 1947; SINZIG, 1910).
\end{abstract}

Keywords: Vozes de Petrópolis Magazine. Franciscans. History of Brazilian Education.

\title{
REVISTA VOZES DE PETRÓPOLIS - LA PRÉSENCE DES FRANCISCAINS DANS L'ÉDUCATION BRÉSILIENNE PAR IMPRESSION
}

\section{RÉSUMÉ}

Ces recherches en cours ont pour objet l'étude du magazine Vozes de Petrópolis, édité par des franciscains au Brésil et mis en circulation entre 1907 et 2003 par la maison d'édition Vozes. Ces recherches, aligné avec la ligne de recherche Rastros: patrimônio cultural franciscano e educação, vise à analyser la présence des franciscains dans l'éducation brésilienne à travers des documents imprimés. Historique et qualitative, la méthodologie privilégie l'analyse documentaire du contexte socio-culturel de l'époque (BENJAMIN, 2012), les luttes et les résistances de l'Église catholique (LEÃO XIII, 1878), l'histoire de la lecture (CHARTIER, 1990 e 2002; DARNTON, 1992 e 2010) et la présence des franciscains dans l'histoire de l'éducation brésilienne (RÖWER, 1947; SINZIG, 1910).

Mots-clés: Magazine Vozes de Petrópolis. Franciscains. Histoire de l'éducation brésilienne.

\section{INTRODUÇÃO}

Enquanto objeto cultural, o tema revista Vozes de Petrópolis - a presença dos Franciscanos na educação brasileira por meio dos impressos se inscreve em duas áreas temáticas e investigativas amplas, a saber, a imprensa e a história ou historiografia da educação. Sob diferentes enfoques, tal objeto cultural já veio a ser abordado por algumas outras análises publicadas, viabilizadas por fundamentação teórica e orientação metodológica afins. No entanto, o presente artigo busca responder à seguinte questão: de que modo se deu a presença dos Franciscanos na educação brasileira por meio da revista Vozes de Petrópolis? 


\section{$(\mathrm{cc})$ EY}

Considerando a intencionalidade da linha de pesquisa Rastros: patrimônio cultural franciscano e educação, o objetivo geral desta investigação é analisar a presença dos Franciscanos na educação brasileira por meio de impressos. Dois são os objetivos específicos desta pesquisa em andamento: diagnosticar as motivações iniciais que levaram os Franciscanos a editar e colocar em circulação a revista Vozes de Petrópolis; relatar dados a respeito da periodicidade da revista nos seus noventa e seis anos de produção e circulação, assim como suas modulações de títulos.

Compreende-se patrimônio como possibilidade de se achegar de indícios históricos de um determinado impresso, no caso a revista Vozes de Petrópolis, editada pelos Franciscanos entre os anos 1907 e 2003. Enquanto patrimônio cultural franciscano e sua relação com a educação brasileira no período, a revista Vozes de Petrópolis está, acima de tudo, sob condição de interpretação diversa. Em sentido amplo, compreende-se patrimônio como 'lugar' de interlocução e de intercâmbio entre pesquisadores, cuja materialidade e/ou não materialidade está condicionada a análises que podem se ater a fatores oriundos: do contexto, das relações, das questões sociais; das tratativas de persuasão; dos costumes, das culturas escolares, eclesiais, sociais e familiares; das ideias pedagógicas, das memórias individuais, coletivas, oficiais e não oficiais; das alteridades, dos conflitos, das disputas, das múltiplas formas de verdades enunciadas, dos diversos interesses em jogo etc.

Em face ao escopo da pesquisa, a metodologia é de natureza histórica e qualitativa que pressupõe, além da descrição dos procedimentos indicados, uma revisão de literatura e de análise documental com base numa escolha teórica para abordar e analisar o objeto de estudo privilegiado. Metodologia esta que se constitui no cotejo com o contexto sociocultural do período (BENJAMIN, 2012), com as lutas e resistências da Igreja Católica (LEÃO XIII, 1878), com os estudos de história da leitura (CHARTIER, 1990, 2002; DARNTON, 1992, 2010) e com a presença dos Franciscanos na história da educação brasileira (RÖWER, 1947; SINZIG, 1910).

A metodologia é mais do que uma circunscrição teórica. Ela é, segundo alguns historiadores, um modo de compreender e de analisar determinado objeto sob investigação. $\mathrm{O}$ historiador francês Roger Chartier é um deles. De acordo com Chartier (1990, p. 33), o historiador é aquele que, do ponto de vista metodológico, concebe os impressos:

[...] não apenas como objeto de leitura, mas como um instrumento que desvenda a cultura da humanidade ao longo dos séculos. Sua atenção volta-se para a reação 
das sociedades diante das alternativas de acumular documentos ou destruí-los para não serem soterradas sob sua própria produção escrita.

E uma das condições para se apreender a reação das sociedades (acumular e/ou destruir) documentos é não perder de vista que a história das práticas de leitura tem por objetivo "[...] identificar para cada época e para cada meio as modalidades partilhadas de ler - aos quais dão formas e sentidos aos gestos individuais" (CHARTIER, 1990, p. 122).

$\mathrm{O}$ posicionamento metodológico do historiador não se reduz a um modo de compreender ou de analisar o objeto de estudo. A metodologia leva o historiador também a perceber contrastes nas maneiras de ler, nas convenções e nas modulações das práticas de leitura, assim como nos “[...] produtos historicamente diversos (livros e imagens, sermões e discursos, canções, romancesfotográficos ou programas de televisão)" (CHARTIER, 2002, p. 53).

Darnton (1992, p. 200) acrescenta que na metodologia é importante questionar a apropriação dos impressos, visto que “[...] a leitura possui uma história. Mas como recuperá-la?". Isso denota que a análise de um impresso, nesta pesquisa o periódico Vozes de Petrópolis, não se restringe somente à materialidade dos seus textos, muito menos ao mundo do leitor. Abrange também um olhar sobre o trabalho de edição do periódico, as mudanças no suporte material dos textos, a ponto de o tratamento dos dados associar tanto análise textual com o que ele chama de pesquisa empírica.

Com base nesses pressupostos metodológicos, foi realizada uma primeira organização do material pertinente ao objeto da pesquisa, quando se tornou indispensável olhar para o conjunto de fascículos de forma analítica. O critério estabelecido para tal organização foi ater-se à fonte documental, ou seja, à revista Vozes de Petrópolis. Nesta fase, as leituras e os fichamentos tiveram papel central, mais especificamente em relação à periodicidade de publicações da revista, assim como das modulações de títulos entre 1907 a 2003.

Nesse sentido, a pesquisa a respeito da Revista Vozes de Petrópolis é, antes de tudo, um embate investigativo complexo, desafiador e, ao mesmo tempo, fundamental para se compreender a presença dos Franciscanos na história da educação brasileira (GILZ, 2018; SOUZA, 2012). Presença franciscana essa eivada de um prestígio durante os primeiros séculos após à chegada, por volta de 1500, à quase extinção nas últimas décadas do século XIX. Em que sentido?

É o que principalmente no primeiro tópico deste artigo estará sendo identificado e discutido. 


\section{(cc) $\mathrm{EY}$}

\section{OS FRANCISCANOS NA EDUCAÇÃO BRASILEIRA}

A presença dos Franciscanos no campo da educação e cultura remonta às origens da fundação da própria Ordem Religiosa, inícios do século XII. São Francisco de Assis, logo após discernir e enunciar a todos o seu propósito de vida, apercebeu-se procurado por outros jovens de Assis (Itália) e, alguns deles, já portadores de formação acadêmica e atuação docente em renomadas universidades, tais como Paris e Oxford: Boaventura de Bagnoregio, Guilherme de Ockham, João Duns Scotus, Raimundo Lúlio, Roger Bacon, entre outros. A tradição com relação à presença dos Franciscanos no campo da educação e da cultura atravessou os séculos seguintes em todos os países onde tais religiosos vieram a se estabelecer e a atuar (MIRANDA, 1969).

A presença dos Franciscanos passou a ocorrer a partir da última década do século XVI, em se falando do Estado brasileiro do Rio de Janeiro, mais precisamente a partir do ano de 1592 por meio de Frei Antônio dos Mártires e Frei Antônio das Chagas. Chegaram a cidade do Rio de Janeiro, procedentes do estado do Espírito Santo a mando do Frei Melquior de Santa Catarina, o primeiro superior responsável pelos Franciscanos no Brasil (RÖWER, 1945). Por que essa menção ao Estado do Rio de Janeiro? Porque em tal Estado se localiza a cidade de Petrópolis, local da edição e impressão da revista Vozes de Petrópolis em meados do ano de 1907. E, anterior à chegada desses primeiros Franciscanos a cidade do Rio de Janeiro, já estavam estabelecidas algumas ordens religiosas entregues tanto ao ofício da evangelização como da educação dos seus interlocutores: a Ordem Jesuíta desde 1568, a Ordem Beneditina desde 1589 e a Ordem dos Carmelitas desde 1590 (CARVALHO; RIBEIRO; SILVA, 2011).

Nos registros das atividades dos Franciscanos no Estado do Rio de Janeiro se sobressai o prestígio que eles tinham junto à Coroa de Bragança, em Portugal. Por exemplo, no ano de 1808 o príncipe regente nomeou pregadores da Capela Real os Freis Antônio de Santa Úrsula Rodovalho, Francisco de São Carlos e Francisco de Santa Teresa de Jesus Sampaio. Por motivo de sua devoção a São Francisco, Dom João VI costumava ir passar o dia 4 de outubro com os Franciscanos no convento Santo Antônio, situado na cidade do Rio de Janeiro, fazendo questão de servir-se dos mesmos talheres utilizados por esses religiosos e da mesma comida. Teria Frei Francisco de Santa Teresa de Jesus Sampaio até presidido a elaboração de um manifesto, assinado por oito mil pessoas, cuja influência no movimento da Independência do Brasil levou o príncipe D. Pedro dar a resposta 


\section{$(c)$ EY}

do Fico em 1822. Além do mais, teria feito também Frei Francisco de Santa Teresa de Jesus Sampaio o sermão na cerimônia da sagração de D. Pedro, entre outras tratativas (RÖWER, 1945).

Consta, no entanto, que a partir da segunda metade do século XIX passa a ocorrer o enfraquecimento não só da presença dos Franciscanos no Brasil como também das diversas ordens religiosas à mercê de medidas tomadas pela instância governamental do Império, seja espoliando tais Ordens dos já escassos bens que utilizavam para formar e educar cristãmente os brasileiros a quem serviam, seja apropriando-se de suas habitações para fins públicos. "O declínio atingia seu ápice quatro anos depois [da Lei de Terras de 1850], com um decreto promulgado pelo ministro da Justiça, Nabuco de Araújo, proibindo a admissão de noviços em todas as ordens religiosas no Brasil" (CARVALHO; RIBEIRO; SILVA, 2011, p. 67).

Tais medidas levaram os Franciscanos a passar sérias necessidades financeiras e, praticamente, à quase extinção total de seus membros no exercício de suas atividades. "Por mais de uma vez haviam os frades apelado para o governo, pedindo que lhe fosse dado reabrir o seu noviciado. [...] tudo em vão. Os conventos, desabitados, não resistiam à inclemência do tempo. [...] Tal era a triste situação [...], quando, em 1889, baqueou o Império” (FREITAS, 1922, p. 53).

O status de liberdade de atuação dado às ordens religiosas no Brasil pelo recém instituído governo republicano possibilitou aos Franciscanos recompor o plantel de seus membros recrutando a partir de 1891, para tanto, religiosos da mesma Ordem provenientes principalmente da Alemanha (CARVALHO; RIBEIRO; SILVA, 2011). No Estado do Rio de Janeiro no Brasil, tal recomposição se deu por meio da reocupação de igrejas arruinadas pela ausência ou pela quase escassa presença de tais religiosos, abrindo escolas contíguas a elas. Tal contexto é fundamental para compreendermos a trajetória dos Franciscanos e sua presença na educação brasileira nas suas mais diversas modulações, ou seja, chegada, primeiros séculos, tensões, incertezas e quase extinção a partir de meados do século XIX.

Na cidade de Petrópolis desse mesmo Estado, os Franciscanos abriram, a saber, no final do ano de 1896 uma escola contígua à Igreja do Sagrado Coração de Jesus. Tratava-se da Escola Gratuita São José que, no dia 5 do mês de março de 1901, passou a dispor de uma tipografia com a finalidade inicial de viabilizar a impressão dos principais materiais didáticos utilizados nas atividades acadêmicas e de evangelização. Aos Franciscanos, a escola foi, nesse período, bem mais do que uma instituição civilizadora e emancipatória do povo. Foi compreendida como fator de 


\section{(cc) EY}

nucleação e espaço de evangelização da comunidade a ponto de levá-la, por si própria, a defender a fé, a religião e os costumes católicos (SCHAETTE, 1922).

Construir escolas contíguas a templos religiosos foi, nesse sentido, um meio adotado pela Igreja Católica para resistir ao ensino laico adotado pelo regime republicano no Brasil como em outros países em que tais medidas já se encontravam em curso, ofertando uma instrução tanto acadêmica como religiosa à luz dos valores cristãos. Foi também um modo de responder à demanda de formação e conformação de cidadãos saudáveis, civilizados e escolarizados (LEÃO XIII, 1878; FREITAS, 1922).

Além de livros de leitura de uso didático para o âmbito da instrução primária, os Franciscanos de Petrópolis optaram pela edição de outros impressos, tais como:

- Compêndios de gramática, de aritmética, de geografia, de História do Brasil, de silabários.

- História Sagrada e Catecismos;

- Obras de outros gêneros, por exemplo, livros hagiológicos, livros de piedade, livros ascéticos, romances e a revista Vozes de Petrópolis.

As motivações iniciais que levaram os Franciscanos a editar e a colocar em circulação tais impressos e, dentre eles, a revista Vozes de Petrópolis convergem para um modo de presença, de atuação editorial e educacional alinhadas às prerrogativas da Igreja Católica no período, o que a seguir será abordado.

\section{ANÁLISE DO OBJETO DA PESQUISA}

A análise do objeto de pesquisa pauta-se na questão que a mobiliza: de que modo se deu a presença dos Franciscanos na educação brasileira por meio da revista Vozes de Petrópolis?

Nos parágrafos anteriores, vários aspectos em relação à referida questão já foram mencionados e abordados. A seguir, pretende-se desenvolver uma análise com base em algumas categorias que durante o percurso da pesquisa foram se evidenciando, a saber: o contexto sociocultural, a história da imprensa, as prerrogativas da Igreja Católica e a revista Vozes de Petrópolis em si. 


\section{(cc) EY}

Em relação ao contexto sociocultural inerente ao objeto de pesquisa, mudanças estruturais ocorriam no final da primeira década do século XX em âmbito nacional. Desde o final do século XIX aspirava-se no Brasil pelo alcance de um patamar de modernidade: o progresso, a civilidade, as promessas governamentais em termos de invenções, avanços da técnica (a luz elétrica, o telégrafo, a locomotiva) atravessados por ambiguidades, conflitos, engodos e falácias.

Ambiguidades, conflitos, engodos e falácias que se alinham a um modo de se compreender a história restrita à ideia de um progresso ascendente e homogêneo em marcha, ao invés de compreendê-la como uma construção plena de 'agoras'.

A ideia de um progresso da humanidade na história é inseparável da ideia de sua marcha no interior de um tempo vazio e homogêneo. A crítica da ideia do progresso tem como pressuposto a crítica da ideia dessa marcha. A história é objeto de uma construção cujo lugar não é o tempo homogêneo e vazio, mas um tempo saturado de 'agoras'. (BENJAMIN, 2012, p. 249).

'Agoras' de uma época que se delineava em meio ao fausto, à predileção pelo luxo e suas ambiguidades. "Dos inventos fundamentais aos mais surpreendentes, das grandes estruturas aos pequenos detalhes, uma cartografia de novidades cobria os olhos desses homens, estupefatos com suas máquinas maravilhosas" (COSTA; SCHWARCZ, 2000, p. 10).

Foi em tal época que se manifestaram com maior intensidade as lacunas humanitárias em relação aos beneficiados com a abolição da escravidão, com a necessidade da implantação de novas fábricas, com o embate em relação aos direitos da classe operária, com as desconexões entre o fenômeno do crescimento urbano e com o aumento da delinquência e criminalidade (ALVIM, 1998; FAUSTO, 1984).

O assentamento de significativos contingentes de famílias de imigrantes estrangeiros no território brasileiro era também um dos outros problemas a ser enfrentado, sem impor a tais famílias o apagamento dos hábitos de morar, de se alimentar, de realizar práticas religiosas, educacionais e sanitárias próprias de seus países de origem.

[...] é nesse período que populações inteiras, cujo horizonte estava circunscrito às aldeias nativas e o comportamento pautado por regras seculares, que passavam de pai para filho pela via oral, viram-se atiradas num vasto mundo de anônimos. Europeus, africanos e asiáticos, portadores de culturas e hábitos tão díspares, passaram a conviver entre si, obedecendo a regras controladas não mais pelas comunidades a que pertenciam e onde todo o mundo se conhecia, mas por 
autoridades impalpáveis e invisíveis como as do Estado, da burguesia naval que os transportava de um lado ao outro do mundo, de novos donos de terras ou indústrias, seus novos patrões nas terras de adoção. (ALVIM, 1998, p. 216).

A imprensa é uma outra categoria de análise que a investigação desenvolvida passou a evidenciar. E, enquanto tal, a imprensa é um dos fatores que também não pode ser subestimado na investigação a respeito das motivações dos Franciscanos para editar e colocar em circulação a revista Vozes de Petrópolis. A imprensa é, por assim dizer, a sístole e a diástole do pensamento humano, “[...] desde a Antiguidade até os dias atuais" (PAIVA, 2010, p. 11). O conceito imprensa advém da expressão prensa móvel e/ou tipos móveis, constituídos inicialmente por caracteres alfabéticos ou numéricos gravados em conjuntos de madeira ou de chumbo com a finalidade de formar palavras, frases e até mesmo textos e, posteriormente, imprimi-los conforme uma estimada quantidade.

Atrelado ao conceito imprensa está o processo gráfico que ganhou aprimoramentos a partir dos estudos e dos ensaios desenvolvidos pelo alemão Johannes Gutenberg no século XV (SOUSA, 2003). Aprimoramentos estes que se tornaram possíveis com a ampliação gradativa das técnicas tipográficas, viabilizando otimização de custos e a versatilidade em termos de impressão de exemplares os mais diversos de textos, obras, boletins, jornais, revistas, entre outros.

Carvalho, Araújo e Gonçalves Neto (2002, p. 72) entendem que:

[...] a imprensa, ligada à educação, constitui-se em um 'corpus documental' de inúmeras dimensões, pois se consolida como testemunho de métodos e concepções pedagógicas de um determinado período. Como também da própria ideologia moral, política e social, possibilitando aos historiadores da educação análises mais ricas a respeito dos discursos educacionais, revelando-nos, ainda, em que medida eles eram recebidos e debatidos na esfera pública, ou seja, qual era a sua ressonância no contexto social.

Sem menosprezar o período anterior no qual se deu a evolução das formas rupestres e da escrita, identificam-se mais de quatro séculos de tempo entre os inventos desenvolvidos por Johannes Guttenberg e o processo de instauração da imprensa no Brasil no início do século XIX. O Brasil colonial era, segundo Lustosa 2004, p.7,:

[...] um dos únicos países do mundo, excetuados os da África e da Ásia, que não produzia palavra impressa. Até 1808 , data da chegada de d. João VI, as letras

Rev. Iberoam. Patrim. Histórico-Educativo, Campinas (SP), v. 6, p. 1-18, e020012, 2020. 
impressas eram proibidas aqui. As poucas tentativas de se estabelecerem tipografias esbarraram na intransigência das autoridades portuguesas. Imprensa, universidades, fábricas - nada disso nos convinha, na opinião do colonizador.

No entanto, nesse mesmo espaço de tempo, a imprensa já havia se efetivado no mundo como meio disseminador de obras, de saberes, de inventos, de fatos e de acontecimentos inerentes às mais diversas esferas da sociedade humana: a tipográfica, a iconográfica, a literária, a cultural, a social, a monástica, a artística, a eclesiástica, a teológica, a política, a econômica, a industrial, a filosófica, a jurídica, a jornalística, a educacional, a científica, entre outras. No Brasil, tal processo de efetivação da imprensa viria a se dar somente a partir de meados da década de 50 do século XX, tal como assegura Abreu (2002, p. 9): “[...] a imprensa, antes dos anos 50, dependia dos favores do Estado, dos pequenos anúncios populares ou domésticos - os classificados - e da publicidade das lojas comerciais.”.

As prerrogativas da Igreja Católica balizaram tanto o lançamento da revista Vozes de Petrópolis como a edição dos seus fascículos posteriores e, por isso, aqui identificada também como uma das categorias dessa análise. A revista Vozes de Petrópolis veio a ser editada e posta em circulação pelos Franciscanos de Petrópolis no final da primeira década do século XX. Tinham eles ainda muito em conta a solicitação papal feita anos antes por Leão XIII (1886, p. 285), ao assim escrever em sua Carta Encíclica Pergrata Nobis:

[...] é necessário que sejam dirigidos os vossos cuidados àquelas coisas que são impressas e publicadas nos diários ou periódicos. Vós conheceis os tempos [...]. Por um lado, os homens são tomados por insaciável desejo de ler; por outro difunde-se grande quantidade de escritos licenciosos; por esses motivos é difícil poder-se dizer qual grande desventura ameaça cada dia a honestidade dos costumes, qual o grande estrago que produz sobre a integridade da religião. Sede perseverantes com a exortação, com a admoestação, servindo-vos de todos os meios e métodos de que dispondes no propósito de revoar os homens desta espécie de fontes corrompidas, e de acompanhá-los à fontes salubres. Será de muitíssima valia se, a vosso cuidado e sob a vossa orientação, forem [...] sustentando a verdade, a virtude e a religião.

Não isenta dessas e de outras inquietações tanto papais como socioculturais da época, a revista Vozes de Petrópolis teve a sua primeira edição em 1 de julho de 1907. Dados a certos temores da Igreja Católica e porque não dizer também dos Franciscanos porta-vozes do ideário católico, a revista passou a ser editada e posta em circulação, visando fazer frente a um conjunto 


\section{(cc) $\mathbf{E Y}$}

de tendências tais como: o laicismo do Estado; a apostasia manifestada pela sociedade moderna em relação às doutrinas católicas, balizada principalmente pelo socialismo, pelo comunismo, pelo niilismo, pela maçonaria, pelo naturalismo político, pelo racionalismo e pelo liberalismo; a separação entre Estado e Igreja na França e em muitos outros países); a instituição da obrigatoriedade do casamento civil anterior cuja união passava a estar à mercê da possibilidade do divórcio; a ênfase dada ao ensino público e à imprensa sob pretexto de suprimir o direito da igreja de instruir e educar a juventude, entre outras (cf. LEÃO XIII, 1878; LEÃO XIII, 1880; LEÃO XIII, 1884; LEÃO XIII, 1885; LEÃO XIII, 1888; LEÃO XIII, 1890; LEÃO XIII, 1891; SINZIG, 1910; SINZIG, 1911).

A categoria revista Vozes de Petrópolis em si não pode ser vista e nem considerada de modo estanque ou isolado. Ela compõe e complementa, a seu modo, a análise desenvolvida das outras categorias mencionadas: o contexto sociocultural, a história da imprensa e as prerrogativas da Igreja Católica.

A revista Vozes de Petrópolis foi criada pelos Franciscanos para servir a modo de uma voz católica ante as tendências adversas ao ideário católico nos mais diversos campos da atividade humana. "Uma revista de cunho, a princípio, mensal, religiosa, científica e literária e uma resposta à necessidade de oferecer ao povo uma leitura civilizadora e moralizadora, de artigos variados e de interesse geral" (EDITORIAL, 1908, p. 1-2). Em outras palavras, essa revista caracterizou-se por contemplar assuntos das mais diversas naturezas da época em cada uma das suas edições, privilegiando não só o aspecto religioso.

A publicação da revista Vozes de Petrópolis constituiu importante fator no desenvolvimento da tipografia da Escola Gratuita São José. Ao alcançar adoção e distribuição por todos os Estados do Brasil, levou a toda parte o nome dos Franciscanos de Petrópolis e da sua obra editorial (ANDRADES, 2001).

A consequência? A 'filha', no caso a revista Vozes de Petrópolis ficar mais conhecida que a mãe, ou seja, a tipografia da Escola Gratuita São José, hoje Editora Vozes (PIMENTEL, 1951, p. 10). Quando ela completou 60 anos em 1967, chegou a receber homenagem na Academia Brasileira de Letras e em algumas Academias de Letras estaduais e Câmaras municipais.

A revista Vozes de Petrópolis teve - nos seus noventa e seis anos e meio de produção e circulação - uma periodicidade mensal no início, quinzenal depois, novamente mensal e, a partir da década de 50 do século XX, bimestral. As mudanças de periodicidade foram pistas importantes 


\section{$(\mathrm{cc}) \mathbf{E Y}$}

para se adentrar no percurso que logrou a ampliação da adoção e da circulação do periódico. Ramos $(2005$, p. 8) constatou em suas pesquisas que “[...] a história dos periódicos ainda seria uma vasta área para possíveis investigações, considerando novas/diferentes abordagens e problemáticas, bem como períodos ainda não trabalhados [...].”.

Assim como as categorias contexto sociocultural, a história da imprensa e as prerrogativas da Igreja Católica, a análise investigativa da revista Vozes de Petrópolis expõe um dos modos da presença dos Franciscanos na história da educação brasileira. Catani (1996, p. 117) destaca que as revistas “[...] de modo geral, constituem uma instância privilegiada para a apreensão dos modos de funcionamento do campo educacional [...]".

Dado as categorias analisadas, cabe ainda ressaltar outros aspectos que também dizem respeito ao modo como se deu a presença dos Franciscanos na educação brasileira por meio do impresso, revista Vozes de Petrópolis. Para Bastos (2007, p. 167),

A imprensa é um corpus documental de vastas dimensões, pois se constitui em um testemunho vivo dos métodos e concepções pedagógicas de uma época e da ideologia moral, política e social de um grupo profissional. É um excelente observatório, uma fotografia da ideologia que preside. Nessa perspectiva, é um guia prático do cotidiano educacional e escolar, permitindo ao pesquisador estudar o pensamento pedagógico de um determinado setor ou de um grupo social a partir da análise do discurso veiculado e da ressonância dos temas debatidos, dentro e fora do universo escolar.

Se em 1942, o impresso cultural, religioso, científico e literário, objeto desta presente pesquisa, passou a se chamar Vozes - Revista Católica de Cultura, no ano de 1969 receberia outra denominação: Revista de Cultura Vozes. Uma mudança sem avisos ou alardes, mas permeada pela clareza quanto às motivações dos Franciscanos com a alteração do título: evitar reducionismos que o termo 'católica' poderia estar agregando à revista no imaginário dos seus interlocutores, assim como dialogar com o contexto da época e seus mais variados problemas, sem dicotomizar profano e sagrado, mundo e história. No ano de 1993, o referido impresso cultural, religioso, científico e literário receberia sua última mudança de nomenclatura: Cultura Vozes. Uma mudança não de titulação, mas também de tamanho e de formato, características que lhe haviam sido mantidas desde sua criação desse impresso (NEOTI, 2007).

Em meio à identificação dos diferentes títulos que a revista recebeu durante os seus noventa e seis anos flagra-se um posicionamento adverso aos impressos, de modo especial na primeira 


\section{$(\mathrm{cc}) \mathbf{E Y}$}

década do século XX, que levou os Franciscanos a editar e a colocar em circulação a revista Vozes de Petrópolis. Posicionamento adverso este em relação à mentalidade positivista e liberal da época e, por isso, opositora do ideário cristão católico de ensino, formação e cultura do cidadão brasileiro. (SINZIG, 1911). Mentalidade positivista e liberal a endossar o ideário de um Estado laico por parte do governo republicano. Tanto que no ano de 1910, há apenas três anos após a publicação da primeira edição da Revista Vozes de Petrópolis, os Franciscanos de Petrópolis assumiram as rédeas em termos da organização e da atuação da imprensa católica no Brasil no esteio das orientações da Igreja Católica. Tratava-se do que se denominou na época de Centro da Boa Imprensa e da Liga da Boa Imprensa. As finalidades?

Buscavam alcançar, a princípio, três finalidades específicas: $\left.1 .^{a}\right)$ prover a imprensa com bons artigos, servindo como fontes, cuidando de fundamentadas e rápidas refutações de calúnias contra a Igreja Católica; 2. ${ }^{a}$ ) indicar, contra a miséria literária a edição de bons romances, obras apologéticas, etc.; $3 .^{a}$ ) criar os meios necessários para possibilitar a organização dos católicos na luta em defesa da Igreja (SINZIG, 1911).

Não menos decisivo para se compreender de que modo se deu a presença dos Franciscanos na educação brasileira por meio de impressos e, dentre eles, a revista Vozes de Petrópolis, é a investigação atentar também para possíveis reticências e boicotes desses religiosos às tratativas do Estado e suas proposições em termos de formação acadêmica em curso na época. Bastos (2007, p. 167) considera que a imprensa

[...] constitui um meio indispensável para o conhecimento do que é o sistema de ensino, o que ele representa, por exemplo, no espaço onde se desenvolve e onde se localizam todos os sistemas, teorias e práticas educacionais, de origem tanto oficial quanto privada. [...] Entre as normas impostas pelo poder central e a prática cotidiana, ao nível de classe, a leitura da imprensa pedagógica permite discernir o que se passa ou não, do centro até a periferia (ou do alto até embaixo), revelando, assim, as reticências ou os boicotes que opõem à instituição escolar as diretrizes que recebe. Inversamente, esta imprensa revela a força de inovação e de proposição que o sistema pode ter encoberto.

De acordo com Darnton (2010, p. 191), tal inter-relação entre os impressos e a história da educação “[...] não começou ontem. Vem desde a cultura acadêmica renascentista [...]. Em um curto período de duas décadas, a história do livro se tornou um campo de estudo rico e variado.”.

$\mathrm{Na}$ análise de um impresso como a revista Vozes de Petrópolis faz-se necessário levar em conta que a leitura compreende três aspectos inter-relacionados: “[...] o texto, o objeto que lhe serve 


\section{$(c c)$ EY}

de suporte e a prática que dele se apodera" (CHARTIER, 1990, p. 127). Aspectos esses que não se reduzem abstratamente um ao outro, mas apontam para uma espécie de jogo interativo entre o leitor e os diversos cenários que a ele se apresentam à medida que é tomado pelo dito e pelo não dito de um determinado impresso.

\section{CONSIDERAÇÕES FINAIS}

Os resultados obtidos com a pesquisa possibilitaram compreender o lastro das motivações que mobilizaram os Franciscanos a dispor da revista Vozes de Petrópolis no intuito de oferecer aos seus interlocutores um periódico de cunho religioso, científico e literário por meio de artigos com temáticas diversificadas, não obstante o processo de laicização alavancado no período pelos liberais republicanos. Processo este perfilado de embates que questionavam, principalmente, a condição da Igreja enquanto instituição disseminadora e modeladora da consciência moral do mundo e, por isso, opositora às concepções laicas da educação. A criação do Centro da Boa Imprensa foi um exemplo destes embates travados entre os liberais republicanos, a Igreja Católica e os Franciscanos.

Os resultados desta investigação possibilitaram também apreender a presença dos Franciscanos na educação brasileira por meio de impressos, dentre eles, a revista Vozes de Petrópolis. Presença que se constituiu por meio de um posicionamento explícito desses religiosos a ponto de não apresentar nos seus fascículos uma visão de ciência, de cultura e de conhecimento à sociedade contrária ao ideário católico. Os Franciscanos, em nome do ideário católico e das exortações papais do período, chegaram a orientar os seus leitores e interlocutores a evitar leituras de obras não recomendadas pelas autoridades eclesiásticas. Tal prática se tornou conhecido historicamente como imprimatur (que se imprima), a constar, geralmente, no verso da página de rosto de cada obra por parte das editoras católicas.

Um outro resultado obtido com a análise foi a permanência do termo 'Vozes' nas diferentes mudanças de titulação da revista entre 1907 a 2003. Permanência que evidencia na revista Vozes de Petrópolis um espaço para o registro, no mínimo, de 'vozes' religiosas, literárias e científicas alinhadas ao ideário católico, principalmente em relação às questões e discussões que mobilizaram o Brasil no período. 


\section{REFERÊNCIAS}

ABREU, A. A. de. A modernização da imprensa, (1970-2000). Rio de Janeiro: Jorge Zahar, 2002.

ALVIM, Z. Imigrantes: a vida privada dos pobres no campo. In: NOVAIS, Fernando. História da vida privada no Brasil, v. 3; Org. Nicolau Sevcenko. São Paulo: Companhia das Letras, 1998.

ANDRADES, M. F. (Org.). Editora Vozes: 100 anos de história. Petrópolis: Vozes, 2001. BASTOS, M. H. C. A imprensa de educação e de ensino: repertórios analíticos, o exemplo da França. Revista Brasileira de Educação, Rio de Janeiro-RJ, v. 12 n. 34 jan./abr., p. 166-168, 2007

BENJAMIN, W. Magia e técnica, arte e política: ensaios sobre literatura e história da cultura. Tradução de Sérgio Paulo Rouanet. Prefácio de Jeanne Marie Gagnebin. São Paulo: Brasiliense, 2012.

CARVALHO, A. M. F. M. de; RIBEIRO, R. M. C.; SILVA, C. A. T. O franciscanismo na cidade e sociedade do Rio de Janeiro. In: CARVALHO, A. M. F. M. de (Coord.). Memória da arte franciscana na cidade do Rio de Janeiro: convento e igreja de Santo Antônio, igreja da Ordem Terceira de São Francisco da Penitência. Rio de Janeiro: Artway/Artepadilla, 2011, p. 47-73.

CARVALHO, C. H; ARAÚJO, J. C. S.; NETO, W. G. Discutindo a história da educação; a imprensa enquanto objeto de análise histórica (Uberlândia-MG, 1930-1950). In: ARAUJO, J. C. S.; GATTI JÚNIOR, D. (Orgs.). Novos temas em história da educação brasileira: instituições escolares e educação na imprensa. Campinas: Autores Associados, 2002, p. 67-89.

CATANI, D. B. A imprensa periódica educacional: as revistas de ensino e o estudo do campo educacional. Educação e Filosofia, Uberlândia-MG, v.10, n.20, p.115- 130, 1996.

CHARTIER, R. A história cultural: entre práticas e representações. Tradução de Mari Manuela Galhardo. Lisboa: Difel; Rio de Janeiro: Bertrand Brasil, 1990.

CHARTIER, R. À beira da falésia: a história entre as incertezas e inquietude. Tradução Patrícia Chittoni Ramos. Porto Alegre: Editora Universidade/UFRGS, 2002.

COSTA, Â. M.; SCHWARCZ, L. M. 1890-1914: no tempo das certezas. SP: Companhia das Letras, 2000.

DARNTON, R. História da Leitura. In: BURKE, Peter (Org.). A escrita da história: novas perspectivas. Tradução de Magda Lopes. São Paulo, Editora da UNESP, 1992, p. 199- 236.

DARNTON, R. A questão dos livros: passado, presente e futuro. São Paulo: Companhia das Letras, 2010.

EDITORIAL. Quo vadis? In: Vozes de Petrópolis, Petrópolis, v. 1, n. 1, p. 1-2, jun., 1908. 


\section{$(\mathrm{cc}) \mathrm{BY}$}

FAUSTO, B. Crime e cotidiano: a criminalidade em São Paulo (1880-1924). SP: Brasiliense, 1984.

FREITAS, D. Resumo histórico da Província Franciscana da Imaculada Conceição do Brasil. In: PROVÍNCIA DA IMACULADA CONCEIÇÃO DO BRASIL. Nas festas do centenário da independência nacional 1822-1922. Petrópolis: Vozes, 1922. p. 9-129.

GILZ, C. Livros de Leitura da Escola Gratuita São José: a presença dos Franciscanos na educação brasileira e na instrução primária em Petrópolis - RJ (1896-1925). 290 f. Tese (Doutorado em Educação) - Programa de Pós-Graduação Stricto Sensu em Educação da Universidade São Francisco, Itatiba, 2018.

LEÃO XIII. Carta Encíclica Arcanum Divinae Sapientie - o matrimônio cristão, 10 de fevereiro de 1880. In: DOCUMENTOS DE LEÃO XIII (1878-1903). Tradução de Honório Dalbosco e Lourenço Costa. São Paulo: Paulus, 2005. p. 99-124.

LEÃO XIII. Carta Encíclica Exeunte Iam Anno - renovação da vida cristã, de 25 de dezembro de 1888. In: DOCUMENTOS DE LEÃO XIII (1878-1903). Tradução de Honório Dalbosco e Lourenço Costa. São Paulo: Paulus, 2005. p. 355-370.

LEÃO XIII. Carta Encíclica Humanum Genus - a maçonaria, de 20 de abril de 1884. In:

DOCUMENTOS DE LEÃO XIII (1878-1903). Tradução de Honório Dalbosco e Lourenço Costa. São Paulo: Paulus, 2005. p. 207-228.

LEÃO XIII. Carta Encíclica Immortale Dei - a constituição cristã dos Estados, de 1 de novembro de 1885. In: DOCUMENTOS DE LEÃO XIII (1878-1903). Tradução de Honório Dalbosco e Lourenço Costa. São Paulo: Paulus, 2005. p. 237-264.

LEÃO XIII. Carta Encíclica In Plurimis - abolição da escravidão, de 5 de maio de 1888. In: DOCUMENTOS DE LEÃO XIII (1878-1903). Tradução de Honório Dalbosco e Lourenço Costa. São Paulo: Paulus, 2005. p. 289-307.

LEÃO XIII. Carta Encíclica Inscrutabili Dei Consilio - início do pontificado, 21 de abril de 1878. In: DOCUMENTOS DE LEÃO XIII (1878-1903). Tradução de Honório Dalbosco e Lourenço Costa. São Paulo: Paulus, 2005. p. 13-23.

LEÃO XIII. Carta Encíclica Libertas - a liberdade humana, de 20 de junho de 1888. In: DOCUMENTOS DE LEÃO XIII (1878-1903). Tradução de Honório Dalbosco e Lourenço Costa. São Paulo: Paulus, 2005. p. 311-341.

LEÃO XIII. Carta Encíclica Nobilissima Gallorum Gens - ordenamento da sociedade doméstica e civil, de 8 de fevereiro de 1884. In: DOCUMENTOS DE LEÃO XIII (1878-1903). Tradução de Honório Dalbosco e Lourenço Costa. São Paulo: Paulus, 2005. p. 193-203. 


\section{$(\mathrm{cc}) \mathrm{BY}$}

LEÃO XIII. Carta Encíclica Pergrata nobis - Estado e Igreja em Portugal, 14 de setembro de 1886. In: DOCUMENTOS DE LEÃO XIII (1878-1903). Tradução de Honório Dalbosco e Lourenço Costa. São Paulo: Paulus, 2005, p. 277-286.

LEÃO XIII. Carta Encíclica Quod Apostolici Muneris - socialismo, comunismo, niilismo, de 28 de dezembro de 1878. In: DOCUMENTOS DE LEÃO XIII (1878-1903). Tradução de Honório Dalbosco e Lourenço Costa. São Paulo: Paulus, 2005. p. 37-48.

LEÃO XIII. Carta Encíclica Quod Auctoritate - convocação de jubileu extraordinário para a renovação dos valores católicos, de 22 de dezembro de 1885. In: DOCUMENTOS DE LEÃO XIII (1878-1903). Tradução de Honório Dalbosco e Lourenço Costa. São Paulo: Paulus, 2005. p. 267-274.

LEÃO XIII. Carta Encíclica Rerum Novarum - sobre a condição dos operários, de 15 de maio de 1891. In: DOCUMENTOS DE LEÃO XIII (1878-1903). Tradução de Honório Dalbosco e Lourenço Costa. São Paulo: Paulus, 2005. p. 419-461.

LEÃO XIII. Carta Encíclica Sapientiae Christiane - os deveres fundamentais dos cidadãos cristãos, de 10 de janeiro de 1890. In: DOCUMENTOS DE LEÃO XIII (1878-1903). Tradução de Honório Dalbosco e Lourenço Costa. São Paulo: Paulus, 2005. p. 383-408.

LUSTOSA, I. O nascimento da imprensa brasileira. 2. ed. Rio de Janeiro: Jorge Zahar, 2004. MIRANDA, Maria do Carmo Tavares de. Os franciscanos e a formação do Brasil. Recife: Universidade Federal de Pernambuco, 1969.

NEOTI, C. Revista Vozes: uma jovem centenária revista de cultura. Ciberteologia: Revista de Teologia \& Cultura. 2007, ano III, n. 14.

PAIVA, A. P. M. de. A aventura do livro experimental. Belo Horizonte: Autêntica; São Paulo: Edusp, 2010.

PIMENTEL, Mesquita. Cinquentenário da Editora Vozes Ltda.: 5 de março de 1901-1951. Petrópolis: Vozes, 1951.

RAMOS, M. E. T. História da educação pelas revistas periódicas. In. SIMPÓSIO NACIONAL DE HISTÓRIA, 23.,2005, Londrina. Anais eletrônicos... Marília: ANPUH, 2005.

RÖWER, B. A Ordem Franciscana no Brasil. 2. ed. Petrópolis: Vozes, 1947.

RÖWER, B. O convento de Santo Antônio do Rio de Janeiro: sua história, memórias, tradições. 3. ed. Petrópolis: Vozes, 1945.

SINZIG, P. Die einzelnen Klöster der Provinz. In: SINZIG, P. Jahrbuch der südbrasilianischen franziskanerprovinz von der Unbefleckten Empängnis. Tradução de Frei Lauro Both. Petrópolis: Vozes de Petrópolis, 1910. p. 43-52. 


\section{(cc) EY}

SINZIG, P. Petrópolis. In: SINZIG, P. Jahrbuch 1910 der Südbrasilianischen Franziskanerprovinz von der Unbefleckten Empfängnis: Im Auftrage des Provinzialates herausgegeben. Tradução de Frei Lauro Both. Petrópolis: Vozes de Petrópolis, 1911. p. 13-21.

SCHAETTE, E. Os religiosos da Província da Imaculada Conceição e a escola. In: PROVÍNCIA DA IMACULADA CONCEIÇÃO DO BRASIL. Nas festas do centenário da independência nacional 1822-1922. Petrópolis: Vozes, 1922. p. 203-229.

SOUZA, C. A. Biblioteca do Instituto Franciscano de Antropologia: histórias e memórias. 2012. 144 f. Tese (Doutorado em Educação) - Faculdade de Educação, Universidade Estadual de Campinas, Campinas, 2012.

SOUSA, J, P. Elementos de teoria e pesquisa da comunicação e dos media. Porto: Universidade Fernando Pessoa, 2003.

Recebido em: 05 de maio de 2020

Aceito em: 25 de junho de 2020 